\title{
EFEK BAHAN BAKAR BIODIESEL DARI MINYAK KEDELAI TERHADAP EMISI GAS BUANG DAN TEMPERATUR RUANG BAKAR MESIN DIESEL
}

\author{
Tulus Burhanuddin Sitorus \\ Departemen Teknik Mesin, Fakultas Teknik, PUI Energi Berkelanjutan dan Biomaterial \\ Universitas Sumatera Utara \\ Email: tburhanudin@yahoo.com \\ Farida Ariani \\ Departemen Teknik Mesin, Fakultas Teknik \\ Universitas Sumatera Utara \\ Email: arianiida@yahoo.com \\ Zulkifli Lubis \\ Departemen Teknik Mesin, Fakultas Teknik \\ Universitas Sumatera Utara \\ Email: msc.zulkifli@yahoo.co.id
}

\begin{abstract}
ABSTRAK
Saat ini bahan bakar biodiesel yang digunakan untuk mesin diesel umumnya berasal dari CPO (crude palm oil). Penelitian ini menggunakan bahan bakar biodiesel dengan bahan baku minyak kedelai. Tujuan penelitian ini selain untuk mengetahui pengaruhnya terhadap kinerja mesin, diteliti juga efeknya terhadap perubahan temperatur di ruang bakar mesin diesel yang diuji dan emisi gas buang yang dihasilkan. Perlu diketahui bahwa perubahan temperatur di ruang bakar sangat mempengaruhi proses pembakaran yang dihasilkan mesin dan hal masih sangat jarang dikaji oleh para peneliti. Metode penelitian diawali dengan pengujian nilai kalor bahan bakar yaitu B30, B20, B10 dan minyak solar. Untuk pengujian kinerja mesin digunakan mesin diesel empat langkah tanpa modifikasi. Dari hasil eksperimental tampak bahwa terjadi peningkatan nilai pemakaian bahan bakar spesifik yang sesuai dengan meningkatnya komposisi biodiesel minyak kedelai di dalam campuran bahan bakar. Besarnya emisi gas buang CO dan HC mengalami penurunan saat menggunakan bahan bakar B10, B20 dan B30. Data eksperimental menunjukkan bahwa daya maksimum diperoleh 1,26 kW, konsumsi bahan bakar spesifik 373,15 g/kWh dan efisiensi termal maksimum 23,04\% saat menggunakan bahan bakar solar. Temperatur maksimum ruang bakar mesin diesel diperoleh saat menggunakan bahan bakar solar sebesar $507,86^{\circ} \mathrm{C}$. Data pengujian menunjukkan bahwa temperatur ruang bakar minimum diperoleh saat mesin diesel menggunakan bahan bakar B30 sebesar $388,49^{\circ} \mathrm{C}$.
\end{abstract}

Kata kunci: minyak kedelai; biodiesel; performansi; emisi gas buang; temperatur ruang bakar.

\begin{abstract}
Currently, biodiesel fuel used for diesel engines generally comes from CPO (crude palm oil). This study uses biodiesel with raw materials from soybean oil. This study aim to knowing its effect on engine performance, it was also investigated its impact on changes in temperature in the diesel engine combustion chamber tested and the resulting exhaust gas emissions. It should be noted that changes in temperature in the combustion chamber significantly affect the combustion process produced by the engine and it is still very rarely studied by researchers. Experimental results show that fuel consumption rise with increasing composition of soybean oil biodiesel in the fuel mixture. The exhaust emissions of CO and HC has decreased when using B10, B20, and B30. Testing data showed that the maximum power was $1.26 \mathrm{~kW}$, fuel consumption $373.15 \mathrm{~g} / \mathrm{kWh}$ and maximum thermal efficiency of $23.04 \%$ when using diesel oil. The maximum temperature of the diesel engine combustion chamber is obtained when using diesel fuel at $507.86^{\circ} \mathrm{C}$. The minimum combustion chamber temperature is achieved when diesel engines use B30 of $388.49^{\circ} \mathrm{C}$, and the heating value of the fuel greatly influences this.
\end{abstract}

Keywords: soybean oil; biodiesel; performance; gas emisions; temperature of combustion chamber. 


\section{PENDAHULUAN}

Peningkatan populasi penduduk dunia semakin membuat permintaan energi semakin tinggi dan hal ini berkorelasi terhadap krisis bahan bakar fosil serta permasalahan pencemaran udara. Kondisi ini juga memberikan tekanan kepada setiap negara untuk segera menggunakan energi terbarukan. Diperkirakan sekitar tahun 2020, Indonesia akan mengimport minyak mentah berkisar 207,2 juta barel setiap tahun. Bila cadangan minyak baru tidak ditemukan maka diperkirakan cadangan bahan bakar minyak akan habis dalam dua dekade mendatang [1]. Biodiesel merupakan energi terbarukan yang dapat dimanfaatkan untuk membantu penghematan pemakaian bahan bakar fosil khususnya minyak bumi [2, 3]. Biodiesel termasuk bahan bakar alternatif yang cukup menjanjikan karena bersifat terbarukan, biodegradable, tidak beracun dan ramah lingkungan $[4,5]$. Penggunaan bahan bakar biodiesel diharapkan juga mengurangi pemanasan global yang terjadi $[6,7]$. Biodiesel telah banyak digunakan pada mesin diesel terutama karena bahan bakunya dapat diperoleh dari berbagai macam seperti minyak tumbuh-tumbuhan, hewan, dan minyak bekas $[8,9]$. Perlu diketahui bahwa jenis bahan bakar yang digunakan cukup mempengaruhi karakteristik dari suatu mesin.

Pemanfaatan energi alternatif menjadi sebuah salah satu terobosan yang dapat memberikan solusi di masa mendatang. Salah satu dari terobosan tersebut adalah dengan memanfaatkan bahan bakar biodiesel dari minyak kedelai. Selain untuk mengetahui pengaruhnya terhadap kinerja mesin, diteliti juga efeknya terhadap perubahan temperatur di ruang bakar mesin diesel yang diuji. Perubahan temperatur di ruang bakar sangat mempengaruhi proses pembakaran yang dihasilkan mesin dan hal masih sangat jarang dikaji oleh para peneliti.

Tujuan dari penelitian ini adalah memanfaatkan biodiesel dari minyak kedelai sebagai bahan bakar mesin diesel sehingga dapat diketahui pengaruhnya terhadap emisi gas buang dan distribusi temperatur ruang bakar yang dihasilkan. Perlu diketahui bahwa pada kedelai terdapat komposisi minyak serta asam lemak yang akibat efek dari varietas dan kondisi iklim tempat tumbuh. Minyak kedelai memiliki titik cair yang cukup tinggi dan pada ruang yang mempunyai temperatur tinggi umumnya memiliki bentuk padat sehingga dapat dimanfaatkan sebagai bahan bakar biodiesel pada musim panas (summer fuel). Penelitian mengenai biodiesel sudah dilakukan para peneliti di seluruh dunia. Sebagian besar riset tersebut menggunakan bahan baku biodiesel dari CPO (crude palm oil). Beberapa penelitian mengenai aplikasi biodiesel pada mesin diesel yang dilakukan di dalam negeri dapat diuraikan sebagai berikut. Penelitian untuk mengkaji efek temperatur terhadap kekentalan biodiesel dari minyak sawit dan kinerja mesin diesel direct injection putaran konstan juga telah dilakukan [10]. Hasilnya bahwa konsumsi bahan bakar meningkat dan daya mesin menurun sehingga efisiensi termal menurun karena efisiensi termal motor bakar merupakan nilai pemanfaatan kalor dari pembakaran bahan bakar menjadi kerja mekanis. Pemamfaatan minyak B10 menghasilkan performa mesin maksimum pada putaran $2550 \mathrm{rpm}$ tanpa perlu memodifikasi mesin dengan bahan bakar biodiesel minyak canola [11]. Sedangkan peningkatan nilai kalor bahan bakar akan membuat penurunan konsumsi bahan bakar dan sebaliknya saat menguji mesin diesel dengan memakai campuran biodiesel dari metil dan etil ester [12]. Untuk pengujian performansi, parameter konsumsi bahan bakar paling sedikit adalah ketika memakai biodiesel B20 diikuti oleh B50 dan B100. Penelitian dengan menggunakan mesin diesel sistem injeksi tak langsung dengan biodiesel dimana sudut dan tekanan injeksi bahan bakar divariasikan sehingga mempengaruhi emisi gas buang yang dihasilkan juga pernah dilakukan [13]. Hasilnya bahwa terjadi pengurangan emisi gas buang untuk HC, CO dan NOx saat memakai biodiesel dari biji jarak dibandingkan bila menggunakan minyak solar untuk kondisi tekanan dan sudut injeksi bahan bakar yang sama.

\section{METODOLOGI PENELITIAN}

\subsection{Bahan}

Bahan bakar yang diuji pada penelitian ini yaitu campuran biodiesel dari minyak kedelai-solar dengan konsentrasi perbandingan yang bervariasi yaitu B30 (biodiesel 30\%-solar 70\%), B20 (biodiesel 20\%-solar 80\%), B10 (biodiesel 10\%-solar 90\%), dan minyak solar. Mesin uji yang digunakan adalah mesin diesel empat langkah dengan spesifikasi pada tabel 1. Gambar 1 menampilkan mesin uji yang digunakan dalam penelitian ini. Pengujian dilakukan tanpa memodifikasi mesin uji diesel. 
Tabel 1. Spesifikasi mesin diesel uji [14]

\begin{tabular}{ll}
\hline Tipe & ROBIN - FUJI DY23D \\
\hline Valve position & Overhead \\
Valve rocker clearance & $0,10 \mathrm{~mm}($ cold $)$ \\
Swept volume & $230 \mathrm{~cm}^{3}$ \\
Bore & $70 \mathrm{~mm}$ \\
Stroke & $60 \mathrm{~mm}$ \\
Compression ratio & 21 \\
Number of cylinder & 1 \\
Power maximum & $3.5 \mathrm{~kW} / 3600 \mathrm{rpm}$ \\
Torque maximum & $10.5 \mathrm{Nm} / 2200 \mathrm{rpm}$ \\
\hline
\end{tabular}
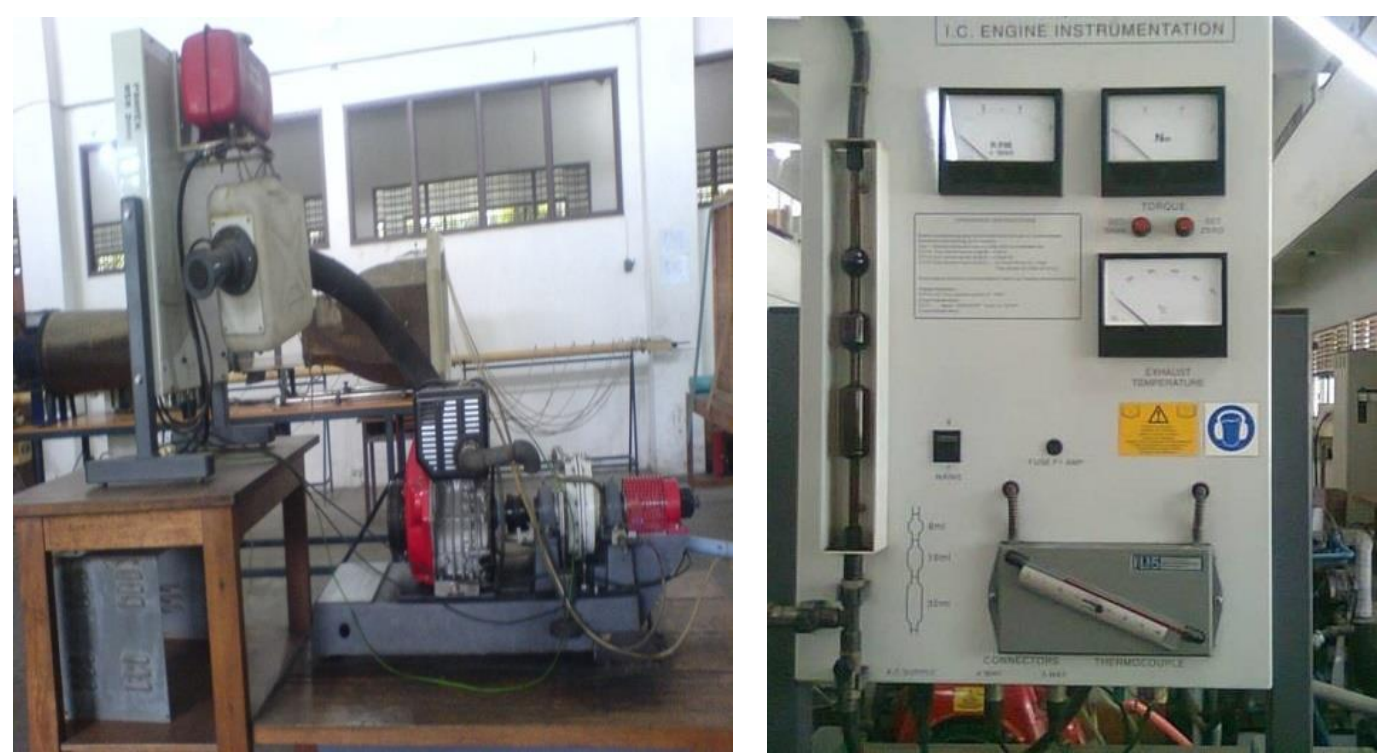

Gambar 1. Mesin Uji Diesel Satu Silinder

\subsection{Skema Eksperimental}

Skema eksperimental dari penelitian ini seperti ditampilkan gambar 2. Mesin uji diesel dengan kapasitas volume ruang bakar $230 \mathrm{~cm} 3$ dipersiapkan dan terhubung dengan peralatan ukur. Instrumen pengukuran yang melekat pada mesin uji terdiri dari torque meter (akurasi $\pm 3 \%$ ), dynamometer (akurasi $\pm 4 \%$ ), dan rotameter (akurasi $\pm 10 \mathrm{rpm}$ ) untuk mengetahui putaran mesin. Alat ukur emisi gas buang gas analyzer (akurasi $\pm 0,01 \%$ ) ditempatkan pada bagian saluran gas buang mesin atau knalpot. Sedangkan untuk mengukur perubahan temperatur di ruang bakar mesin diesel digunakan sensor termokopel (akurasi $\pm 4 \%$ ) yang dimasukkan ke dalam ruang bakar dengan cara melubangi dinding ruang bakar. Termokopel tersebut dihubungkan dengan data akuisisi yang tersambung ke komputer. Proses eksperimental dilaksanakan dengan membuat variasi bahan bakar sesuai perbandingan yang telah ditentukan dengan putaran mesin konstan $1800 \mathrm{rpm}$. 


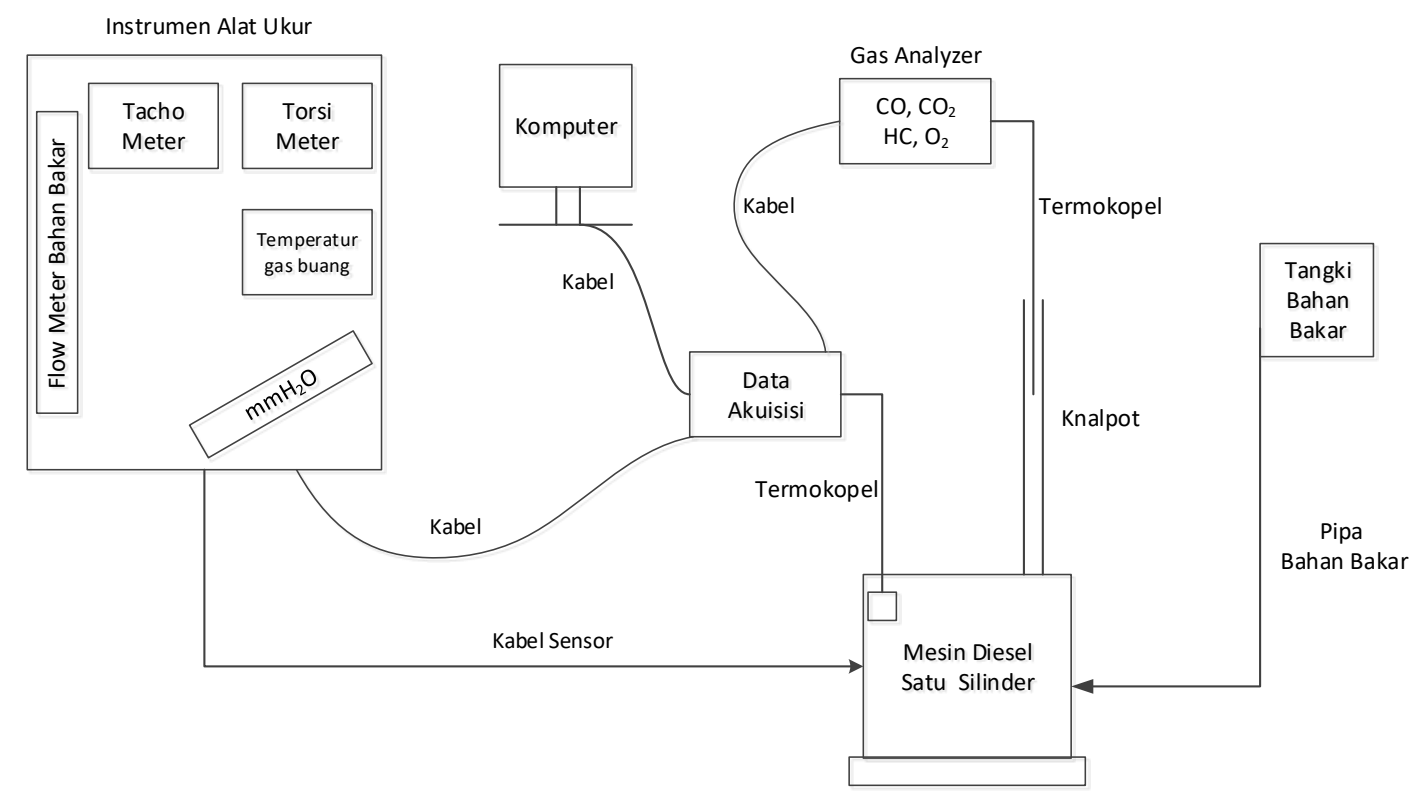

Gambar 2. Skema Eksperimental

\section{HASIL DAN PEMBAHASAN}

\subsection{Bahan Bakar}

Untuk mengetahui nilai kalor maka bahan bakar diuji menggunakan peralatan bomb calorimeter tipe tabung yang memiliki tingkat akurasi $\pm 3 \%$. Setiap sampel bahan bakar diuji sebanyak lima kali. Hasil uji kelima sampel kemudian dirata-ratakan untuk mendapatkan nilai kalor bahan bakar. Hasil pengujian menunjukkan bahwa minyak solar memiliki nilai kalor maksimum $44231 \mathrm{~kJ} / \mathrm{kg}$. Sedangkan B30 memiliki nilai kalor minimum sebesar $38084 \mathrm{~kJ} / \mathrm{kg}$. Perlu diketahui bahwa energi yang dihasilkan saat proses pembakaran dipengaruhi oleh nilai kalor bahan bakar. Disamping itu komposisi penyusun bahan bakar sangat mempengaruhi nilai kalor. Komposisi biodiesel yang semakin tinggi di dalam campuran akan nilai kalor bahan bakar semakin menurun. Penurunan nilai kalor bahan bakar tersebut diakibatkan meningkatnya kadar oksigen dalam komposisi bahan bakar tersebut. Kondisi ini menyebabkan bahwa untuk memperoleh jumlah energi yang sama maka bahan bakar B30 yang dibutuhkan semakin besar.

Tabel 2. Hasil pengujian nilai kalor bahan bakar

\begin{tabular}{lc}
\hline Bahan bakar & Nilai kalor $(\boldsymbol{k J} / \mathbf{k g})$ \\
\hline Solar & 44231 \\
B10 & 41466 \\
B20 & 39996 \\
B30 & 38084 \\
B100 & 35731 \\
\hline
\end{tabular}

\subsection{Performansi Mesin Diesel}

Berdasarkan data eksperimental diperoleh daya maksimum sebesar $1.26 \mathrm{~kW}$ saat mesin diesel menggunakan bahan bakar solar. Daya minimum diperoleh $0.92 \mathrm{~kW}$ saat mesin diesel menggunakan bahan bakar B30. Variabel yang cukup mempengaruhi daya poros suatu mesin adalah torsi. Torsi yang semakin besar akan membuat daya poros yang dihasilkan juga semakin meningkat dan sebaliknya. Kondisi ini disebabkan perubahan daya berbanding linear dengan torsi mesin. Terjadinya penurunan daya poros pada B10, B20 dan B30 dapat juga disebabkan oleh kurang sesuainya setting timing injection, karena bilangan setana biodiesel lebih tinggi dari minyak solar sehingga dibutuhkan ignition delay yang lebih singkat. Karena itu diperlukan usaha untuk memajukan waktu injeksi agar diperoleh daya yang optimal. Pada pengujian ini tidak ada modifikasi pada mesin uji. Konsumsi bahan bakar spesifik maksimum diperoleh 435,38 $\mathrm{g} / \mathrm{kWh}$ saat mesin diesel menggunakan bahan bakar B30. Nilai konsumsi bahan bakar spesifik minimum berkisar $373,15 \mathrm{~g} / \mathrm{kWh}$ saat mesin memakai minyak solar. Data pengujian menunjukkan bahwa konsumsi bahan bakar spesifik saat mesin menggunakan B10, B20 dan B30 mengalami peningkatan. Hal 
ini disebabkan nilai kalor B10, B20 dan B30 yang lebih rendah dibandingkan dengan minyak solar karena adanya oksigen pada biodiesel yang mengakibatkan komposisi udara-bahan bakar menjadi lebih miskin (lean mixture) sehingga untuk memperoleh performansi yang diharapkan maka komposisi udara-bahan bakar harus ditingkatkan (rich mixture). Hal ini membuat bahan bakar yang dibutuhkan menjadi meningkat dibandingkan saat mesin memakai minyak solar. Nilai maksimum efisiensi termal diperoleh sebesar 23,04\% saat mesin menggunakan minyak solar. Besarnya penurunan efisiensi termal bila mesin diesel uji menggunakan bahan bakar campuran adalah berkisar 2-14\%. Perlu diketahui bahwa parameter daya mesin, laju aliran bahan bakar ke ruang bakar dan nilai kalor bahan bakar turut mempengaruhi efisiensi termal motor bakar.

\subsection{Komposisi Emisi Gas Buang}

Pada pengujian ini juga diukur komposisi gas buang yang meliputi karbon monoksida (CO), karbon dioksida $\left(\mathrm{CO}_{2}\right)$, oksigen $\left(\mathrm{O}_{2}\right)$ dan hidrokarbon $(\mathrm{HC})$ dengan menggunakan alat uji emisi gas analyzer pony infragas 205. Data hasil pengukuran emisi gas buang diukur setiap menit selama 10 menit. Tabel 3 menampilkan data rekapitulasi hasil pengukuran emisi gas buang yang dihasilkan selama proses pengujian.

Tabel 3. Data rekapitulasi pengukuran komposisi gas buang

\begin{tabular}{lcccc}
\hline Keterangan & $\boldsymbol{C O}_{2}(\boldsymbol{\%})$ & $\boldsymbol{C O}(\boldsymbol{\%})$ & $\boldsymbol{H C}(\boldsymbol{p p m})$ & $\boldsymbol{O}_{2}(\boldsymbol{\%})$ \\
\hline Minyak solar & 0.6440 & 0.0132 & 26.65 & 19.1021 \\
B10 & 0.7520 & 0.0101 & 23.55 & 19.4460 \\
B20 & 0.7860 & 0.0091 & 21.15 & 19.7720 \\
B30 & 0.8140 & 0.0087 & 18.27 & 20.2110 \\
\hline
\end{tabular}

Hasil pengukuran menunjukkan bahwa saat mesin diesel uji menggunakan bahan bakar B10, B20 dan B30 diperoleh penurunan kandungan karbon monoksida di dalam emisi gas buang berkisar 23,48-34,09\%. Kadar CO yang dihasilkan terjadi karena kurangnya oksigen sehingga proses pembakaran tidak berlangsung secara sempurna. Kondisi ini sebaliknya akan membuat emisi $\mathrm{CO}_{2}$ mengalami peningkatan. Secara umum dapat dikatakan bahwa komposisi penyusun bahan bakar sangat mempengaruhi emisi gas buang dari proses pembakaran. Hal ini memiliki argumentasi bahwa biodiesel memiliki kelebihan atom oksigen sehingga biodiesel merupakan bahan bakar yang bersifat oksigenat yang memiliki kemampuan untuk mengikat molekul $\mathrm{CO}$ menjadi $\mathrm{CO}_{2}$. Penurunan emisi gas buang $\mathrm{HC}$ berkisar $11,62-31,45 \%$. Adanya kadar emisi HC disebabkan oleh proses pembakaran yang kurang sempurna. Penggunaan B10, B20 dan B30 membuat emisi gas buang yang dihasilkan menjadi lebih ramah lingkungan karena biodiesel mempunyai ikatan $\mathrm{OH}$ di pada komposisi molekulnya sehingga proses pembakaran di ruang bakar menjadi lebih sempurna.

\subsection{Temperatur Ruang Bakar}

Pada penelitian ini dikaji juga distribusi perubahan temperatur yang terjadi di ruang bakar mesin diesel. Perlu diketahui bahwa perubahan temperatur di ruang bakar sangat mempengaruhi proses pembakaran yang dihasilkan mesin dan kondisi ini masih sangat jarang dikaji oleh para peneliti. Hal ini juga untuk melihat pengaruh bahan bakar yang digunakan terhadap temperatur ruang bakar yang dihasilkan. Proses pengukuran temperatur ruang bakar dilakukan dengan membuat lubang berdiameter $10 \mathrm{~mm}$ pada dinding ruang bakar. Selanjutnya sensor termokopel temperatur yang terhubung dengan data akuisisi dimasukkan ke dalam ruang bakar dan ditutup dengan baut yang bisa dibuka tutup. Pada data akuisisi diatur rentang waktu pengukuran setiap 0,02 detik selama 100 detik untuk setiap pengujian masing-masing bahan bakar yang digunakan. Dari hasil pengukuran diperoleh temperatur maksimum di ruang bakar mesin diesel saat menggunakan bahan bakar solar sebesar $507,86^{\circ} \mathrm{C}$. Temperatur ruang bakar minimum diperoleh saat mesin diesel menggunakan bahan bakar B30 sebesar $388,49^{\circ} \mathrm{C}$. Temperatur rata-rata ruang bakar yang diperoleh selama pengujian adalah $448,27^{\circ} \mathrm{C}$. Nilai kalor bahan bakar yang digunakan turut mempengaruhi distribusi temperatur di dalam ruang bakar. Kandungan nilai kalor bahan bakar solar yang lebih tinggi dibandingkan dengan B10, B20, dan B30 membuat energi panas yang dihasilkan saat proses pembakaran menjadi lebih besar diterima oleh dinding ruang bakar mesin diesel. Gambar 3, 4, 5 dan 6 menampilkan distribusi temperatur ruang bakar saat memakai minyak solar, B10, B20 dan B30. 


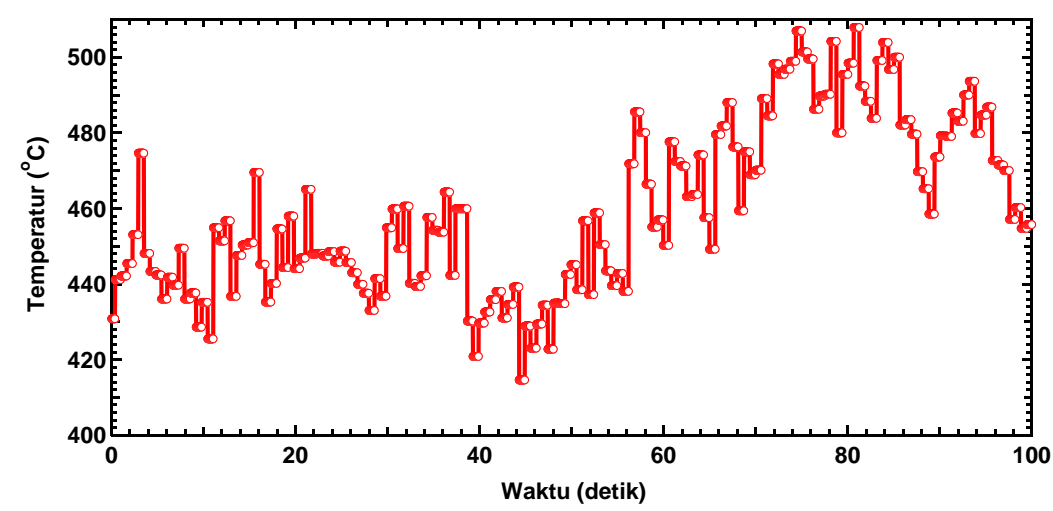

Gambar 3. Distribusi Temperatur Ruang Bakar Menggunakan Bahan Bakar Solar

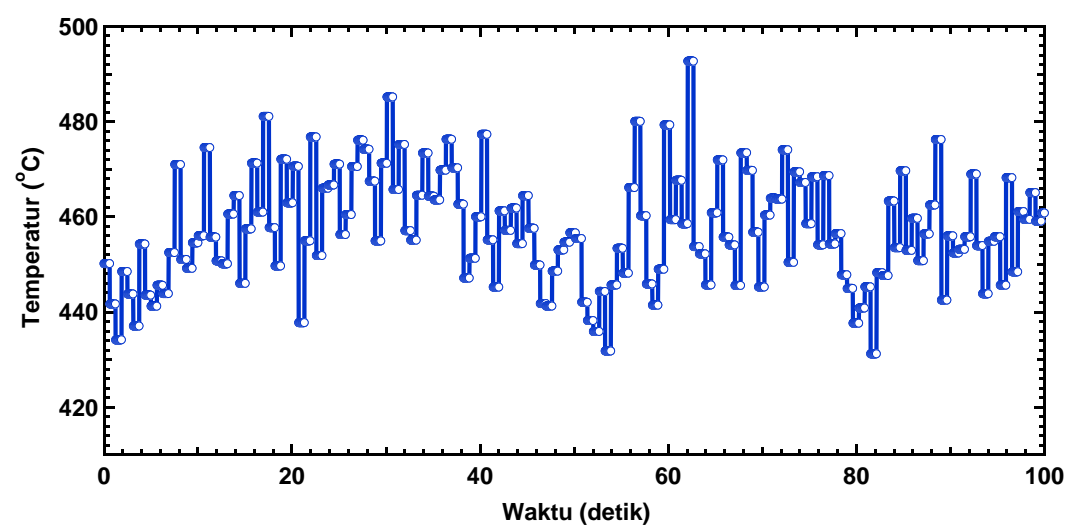

Gambar 4. Distribusi Temperatur Ruang Bakar Menggunakan B10

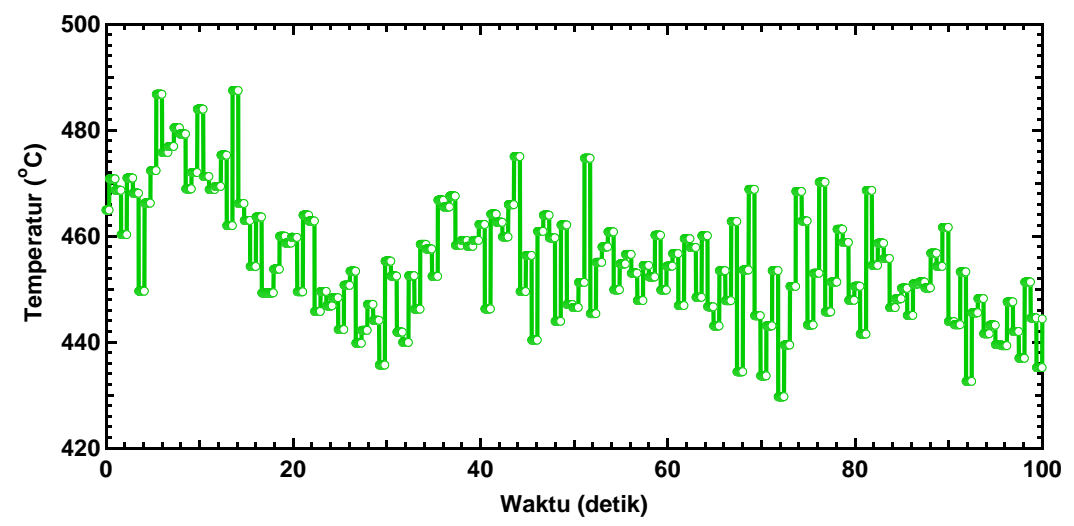

Gambar 5. Distribusi Temperatur Ruang Bakar Menggunakan B20

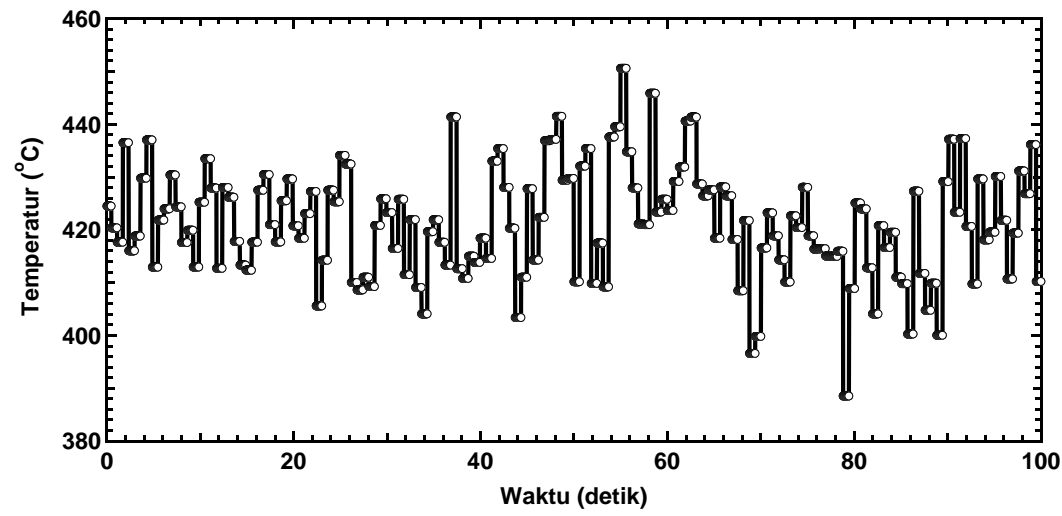

Gambar 6. Distribusi Temperatur Ruang Bakar Menggunakan B30 


\section{KESIMPULAN}

Performansi dan emisi gas buang serta distribusi temperatur ruang bakar dari mesin diesel empat langkah berbahan bakar campuran solar-biodiesel minyak kedelai telah diuji dan dianalisa. Data eksperimental menunjukkan bahwa daya maksimum diperoleh sebesar $1,26 \mathrm{~kW}$, konsumsi bahan bakar spesifik 373,15 g/kWh dan efisiensi termal maksimum 23,04\% saat menggunakan bahan bakar solar. Peningkatan pemakaian bahan bakar terjadi saat menggunakan minyak campuran karena nilai kalor campuran bahan bakar solar-biodiesel minyak kedelai yang lebih rendah dibanding nilai kalor bahan bakar solar. Besarnya emisi gas buang CO dan HC mengalami penurunan saat menggunakan campuran bahan bakar solar-biodiesel. Temperatur maksimum ruang bakar mesin diesel diperoleh saat menggunakan bahan bakar solar sebesar $507,86^{\circ} \mathrm{C}$. Sedangkan temperatur ruang bakar minimum diperoleh saat mesin diesel menggunakan bahan bakar B30 sebesar $388,49^{\circ} \mathrm{C}$. Nilai kalor bahan bakar yang digunakan turut mempengaruhi distribusi temperatur di dalam ruang bakar mesin diesel.

\section{UCAPAN TERIMA KASIH}

Penulis menyampaikan ucapan terimakasih atas dukungan dana dari Universitas Sumatera Utara melalui program penelitian terapan TALENTA tahun 2018.

\section{DAFTAR PUSTAKA}

[1] Aytav, E., \& Kocar, G. (2013). Biodiesel from the perspective of Turkey: Past, present and future. Renewable and Sustainable Energy Reviews, 25, 335-350.

[2] Imdadul, H. K., Masjuki, H. H., Kalam, M. A., Zulkifli, N. W. M., Alabdulkarem, A., Rashed, M. M., ... How, H. G. (2016). Higher alcohol-biodiesel-diesel blends: An approach for improving the performance, emission, and combustion of a light-duty diesel engine. Energy Conversion and Management, 111, 174-185.

[3] Ariani, F., Ginting, E., \& Sitorus, T.B. (2017). Karakteristik Kinerja Mesin Diesel Stasioner dengan Bahan Bakar Campuran Biodiesel dari Biji Kemiri Sunan. Media Teknika Jurnal Teknologi, 12 (1), $36-45$.

[4] Srithar, K., Arun Balasubramanian, K., Pavendan, V., \& Ashok Kumar, B. (2017). Experimental investigations on mixing of two biodiesels blended with diesel as alternative fuel for diesel engines. Journal of King Saud University - Engineering Sciences, 29(1), 50-56.

[5] Sajjad, H., Masjuki, H. H., Varman, M., Kalam, M. A., Arbab, M. I., Imtenan, S., \& Rahman, S. M. A. (2014). Engine combustion, performance and emission characteristics of gas to liquid (GTL) fuels and its blends with diesel and bio-diesel. Renewable and Sustainable Energy Reviews, 30, 961-986.

[6] Al Qubeissi, M., Sazhin, S. S., \& Elwardany, A. E. (2017). Modelling of blended Diesel and biodiesel fuel droplet heating and evaporation. Fuel, 187, 349-355.

[7] Ariani, F., Sitorus, T. B., \& Ginting, E. (2017). The performance and emissions of diesel engines with biodiesel of sunan pecan seed and diesel oil blends. In IOP Conference Series: Materials Science and Engineering (Vol. 277).

[8] Indrawan, N., Thapa, S., Rahman, S. F., Park, J. H., Park, S. H., Wijaya, M. E., ... Park, D. H. (2017). Palm biodiesel prospect in the Indonesian power sector. Environmental Technology and Innovation, 7, 110-127.

[9] Ariani, F., Ginting, E., \& Sitorus, T.B. (2014). Karakteristik Pengaruh Biodiesel dari Limbah Sawit Cair Terhadap Unjuk Kerja Mesin Diesel Empat Langkah. Jurnal Pendidikan Teknologi dan Kejuruan, 16 (2), 32-39.

[10] Studi, P., Teknik, M., Diponegoro, P. P., \& Pembimbing, T. (n.d.). Terhadap Performansi Mesin Diesel (Vol. 1959072219).

[11] Roy, M. M., Wang, W., \& Bujold, J. (2013). Biodiesel production and comparison of emissions of a DI diesel engine fueled by biodiesel-diesel and canola oil-diesel blends at high idling operations. Applied Energy, 106, 198-208.

[12] Knothe, G., \& Razon, L. F. (2017, January 1). Biodiesel fuels. Progress in Energy and Combustion Science. Elsevier Ltd. 
[13] Rashedul, H. K., Masjuki, H. H., Kalam, M. A., Teoh, Y. H., How, H. G., \& Rizwanul Fattah, I. M. (2015). Effect of antioxidant on the oxidation stability and combustion-performance-emission characteristics of a diesel engine fueled with diesel-biodiesel blend. Energy Conversion and Management, 106, 849-858.

[14] Tecquipment Education and Training. Test Bed and Instrumentation for Small Engine. Manual, Ltd 2000. 